\title{
Does a Course in Wellness Education Assist Undergraduate Students on Academic Probation in College Success?
}

Tabitha Young Gast, Anthony A. Michael, Talunja Eskridge, Katherine M. Hermann, and Ian Turnage-Butterbaugh

A group of 223 first-time college freshman on academic probation participated in this study. Participants were mandated to attend a course designed to assist them in adapting to college life though wellness education, counseling, and interventions designed to improve study behaviors. Although pre to post assessment analysis indicated students' GPA improved, their wellness scores did not change. Implications for working with students on academic probation and suggestions for additional research are explored.

College students confront a range of challenges when making the transition from high school to higher education (Schwitzer, Griffin, Ancis, \& Thomas, 1999). Navigating these difficulties often results in a high incidence of psychological distress (Ferry, Tobin, \& Beesley, 2004). In order to assess the health of college students, the American College Health Association (ACHA, 2012) annually surveys students. During fall 2011, the ACHA surveyed 27,774 college students that were in various semesters of their undergraduate studies and posed a range of questions concerning their health and well-being. In the findings, students reported having the following experiences at some point within the last twelve months: First, approximately 30\% felt "so depressed that it was difficult to function." Second, approximately $43 \%$ experienced "more than average stress." In addition, 50\% felt "overwhelming anxiety," 45\% reported they felt "things were hopeless," $86 \%$ felt "overwhelmed by all they had to do," $81 \%$ felt "exhausted" (not from physical

Tabitha Young Gast (tlyoung1@olemiss.edu) is an Assistant Professor of Leadership and Counselor Education at The University of Mississippi.

Anthony A. Michael is an Assistant Professor in Counseling and Psychology at Tennessee Tech University.

Talunja Eskridge is a Doctoral Student in Leadership \& Counselor Education at The University of Mississippi.

Katherine M. Hermann is an Assistant Professor of Counselor Education at University of Louisiana at Lafayette.

Ian Turnage-Butterbaugh is a Doctoral Student Leadership \& Counselor Education at The University of Mississippi. 
activity), 57\% felt "very lonely," and 36\% felt "overwhelming anger." Furthermore, $44 \%$ of the students stated they felt their academic requirements were "traumatic" or "difficult" to handle within the last twelve months. These findings suggest that adjustment to higher education is a struggle for many students, and for some, the challenges may result in academic probation.

Previous studies propose that non-academic variables affect first-year college students' adjustment more than academic ability (Brooks \& Dubois, 1995; Gerdes \& Mallinckrodt, 1994; Johnson, 1997; Petrie \& Russell, 1995; Rickinson \& Rutherford, 1995; Wilson, Mason, \& Ewing, 1997). Given these indicators, colleges and universities are continually attempting to formulate plans to improve student retention and facilitate college careers (Friedman \& Mandel, 2010). Nevertheless, despite these efforts, in the U S, only about one half of students who enter fouryear colleges immediately after high school complete their degrees (Kuh et al., 2005; Sharkin, 2004). Trombley (2001) questioned whether an administration could provide assistance if it does not fully understand the students it is trying to help. In response to questions such as this, Waggoner and Goldman (2005) researched institutions with an ideological focus on creating a "caring and studentfriendly" campus and found that campus environment played an important role in the development of successful student-retention policies. In more recent years, researchers have focused on the difference between successful and unsuccessful college students in an attempt to find the best solutions to assist struggling students (James \& Graham, 2010).

\section{The Wellness Paradigm}

One approach to understanding students' challenges is the conceptualization of a wellness paradigm. Wellness has been defined as "the process and state of a quest for maximum human functioning that involves the body, mind, and spirit" (Archer, Probert, \& Gage, 1987, p. 311). Greenberg (1985) discussed the significance of separating the concepts of health and wellness. When defining health, Greenberg noted social, mental, emotional, spiritual, and physical components. He distinguished wellness as the integration of these components and described high-level wellness as the result of a balance of all of components. While health has traditionally been distinguished as the nonexistence of illness, wellness additionally emphasizes a zest and enthusiasm for life. Therefore, "people can be well regardless of whether they are ill or healthy" (Greenberg, 1985, p. 404). The wellness paradigm surpasses the traditional illness-oriented medical model by advocating for a holistic philosophical basis for development (Myers, 1991). All wellness models appraise psychological well-being, which is envisioned as an internally focused method of attaching value to quality of life and affective experiences (Adams, Bezner, Drabbs, Zambarano, \& Steinhardt, 2000). In these models, wellness is a multidimensional construct including spiritual, psychological, and social variables.

The Wheel of Wellness (WoW) model developed by Myers, Sweeney, and Witmer (2002) incorporates a greater variety of factors contributing to 
holistic wellness, or well-being, than other models. Drawing upon theoretical constructs and empirical research in the fields of psychology, education, sociology, anthropology, behavioral medicine, and religion, the WoW model focuses on optimal health through the integration of the mind, body, and spirit. When compared to the medical or illness model that accentuate disability and disease (Larson, 1999), Myers, Sweeney, and Witmer's (2002) wellness model is an integrative, strengths-based, holistic approach to understanding human functioning (Parker et al., 2001; Snyder \& Lopez, 2002). At this time, the WoW model has been revised into the inventories of the Wellness Evaluation of Lifestyle (WEL) and the Five-factor Wellness Evaluation of Lifestyle (5F-WEL; Myers, Luecht, \& Sweeney, 2004). The college course examined in this research study focused on educating students about wellness (Myers, Sweeney, \& Witmer, 2002) and intervening with students' overall wellness through wellness-focused counseling in an effort to prevent academic withdrawal.

Over the last twenty years, a variety of researchers have investigated individual components of health and healthy behaviors to ascertain their influence on wellbeing. These studies have included assessments of love (Khaleque, 2004; Sanderson \& Cantor, 1997), sense of worth (Crocker, Luhtanen, Cooper, \& Bourette, 2003; Herrero \& Grocica, 2004), spirituality (Trockel, Barnes, \& Egget, 2000), stress management (Aguado Loi, Spencer, \& William, 2008; Hudd et al., 2000; Kim \& Seidlitz, 2002; Thome \& Espelage, 2004), nutrition (Cousineau, Goldstein, \& Franko, 2004), and exercise (Insel \& Roth, 2005). Although findings are significant in recording the influence of individual components on both health and wellbeing, research describing the significance of multiple, concurrent behaviors on wellness in the college population is limited, and no current studies investigate students on academic probation.

\section{Characteristics of Students on Academic Probation}

Literature about students on academic probation reveals a set of broad descriptors and characteristics in defining the population. The most common description is the inability to perform at a standard predetermined by the university or college, which is typically a 2.0 grade point average (James \& Graham, 2010; Tovar \& Simon, 2006). In addition to a low grade point average, students on academic probation display characteristics of poor academic preparation (Tinto, 1993; Trombley, 2001), low levels of motivation (Abelman \& Molina, 2001; Hsieh, Sullivan, \& Guerra, 2007; Smith \& Winterbottom, 1970), poor time-management skills (Balduf, 2009; Proctor, Prevatt, Adams, Hurst, \& Petscher, 2006), and commonly exhibit signs of an external locus of control (Balduf, 2009; Pascarella \& Terenzini, 2005).

A study by Smith and Winterbottom (1970) suggested that students lacked a sense of urgency and demonstrated defensiveness and dependency behaviors. Recently, multiple studies have shown that these students usually have a broad array of excuses for their low achievement, which include transition and adjustment to college life, financial difficulties, family responsibilities, work 
priorities, and unsuitable program choices (Balduf, 2009; Hsieh, Sullivan, \& Guerra, 2007; Pascarella \& Terenzini, 2005; Proctor, Prevatt, Adams, Hurst, \& Petscher, 2006; Tovar \& Simon, 2006; Trombley, 2001). Furthermore, one study showed that students on academic probation are generally younger than the mean age for a college student, male, and confronting multiple issues beyond academics (James \& Graham, 2010). While current literature characterizes students on academic probation by age, gender, personality, and stress variables, several indicate factors other than academics as contributing to students' placement in a retention program. When conceptualizing students in retention programs through a holistic and integrative ideology, the characteristics described by these studies incorporate well in to the components of the wellness paradigm (e.g., Coping Self, Essential Self, Social Self, Physical Self, and Creative Self).

\section{Wellness and Students on Academic Probation}

Current literature evaluating the wellness of students on academic probation remains limited, with most research focusing on student persistence and retention practices (Waggoner \& Goldman, 2005). Nevertheless, Myers and Mobley (2004) contend one of the most important predictors of success in college is the overall wellness of the student. In their study, Myers and Mobley (2004) recorded lower levels of wellness in both traditional and non-traditional college students compared to non-student adults. In particular, Myers and Mobley's (2004) findings showed students scored the lowest on the Coping Self factor and highest on the Social Self factor. Likewise, Hermon and Davis (2004) found significant differences between traditional and non-traditional students on the dimensions of selfregulation, which included realistic beliefs, sense of control, exercise, and self-care.

Research that addresses characteristics of students that are on or at risk for academic probation is limited. This is a surprise given the need to understand and intervene with this population in order to decrease college attrition rates. Furthermore, literature using wellness models to conceptualize students' characteristics that are currently on academic probation is nonexistent. Thus, the purpose of this study was to explore the relationship between wellness and achievement by measuring students currently on academic probations' total wellness using the Five-factor Wellness Evaluation of Lifestyle inventory over the course of a semester.

The researchers explored the following research questions: a) Does semester GPA predict wellness among college undergraduates on academic probation who are receiving wellness-related counseling and education? b) Is there a difference in wellness score within undergraduates on academic probation who are receiving wellness-related counseling and education from pre to post assessment? and c) Does change in wellness predict change in GPA among college undergraduates on academic probation who are receiving wellness-related counseling and education? 


\section{Method}

\section{Design}

This study used a quantitative research design. During the spring of 2012 semester, $223(n=223)$ first-time freshman on academic probation participated in this study. These students were mandated to take a course designed to improve their wellness through wellness education, counseling, and study behaviors, thereby theoretically improving their academic success, with the hope of reducing the university's attrition rates.

In order to determine the necessary sample size to control for Type II errors, an a priori power analysis was calculated for all statistical analyses used within this study. An a priori power analysis for a linear regression, with an alpha of .05, and a power equal to .95 (Cohen, 1992), indicated a sample size of 128 student participants is needed to detect a small, thus conservative, effect size of .6 (Lenth, 2001). An a priori power analysis for a paired samples $t$-test, with an alpha of 05 and a power equal to .95 (Cohen, 1992), determined a sample size of 45 student participants is necessary to detect a small, conservative effect size of .6 (Lenth, 2001). These analyses confirmed that our sample size of 223 student participants was sufficiently robust enough to control for a Type II error.

\section{Measures}

Demographic questionnaire.

Participants completed a demographic questionnaire as part of the Fivefactor Wellness Inventory, during which they reported their gender, age, marital status, ethnicity, and employment status.

Five-factor Wellness Inventory.

This study used the Five-factor Wellness Inventory (5F-Wel; Myers \& Sweeney, 2004) to examine participant wellness for the purposes of this study. This assessment consists of 80 wellness items, which are scored on a four point Likert scale, ranging from strongly agree to strongly disagree. This instrument divides wellness into a composite wellness score, Total Wellness, and five subcategories of wellness. The subcategories of wellness are Creative Self, Coping Self, Social Self, Essential Self, and Physical Self. These five subcategories are further categorized into 17 third-order factors including Intelligence, Emotions, Control, Work, and Positive Humor, which are components of the Creative Self; Leisure, Stress Management, Self-Worth, and Realistic Beliefs, which are components of the Coping Self; Friendship and Love, which are components of the Social Self; Essence, Gender Identity, Cultural Identity, and Self-care, which are components of the Essential Self; and finally, Nutrition and Exercise, which are components of the Physical Self.

Concerning reliability, Hattie, Myers, and Sweeney (2004) reported the alpha coefficients for the five subcategories of wellness on the 5F-Wel were -.93 Creative Self, .92 Coping Self, -.94 Social Self, -.91 Essential Self, and -.90 Physical Self, and 
Myers and Sweeney (2004) reported alpha coefficients of .90 for Total Wellness. This instrument was normed on a population of $n=3,043$ participants and included 54\% males and 46\% females, aged 18 to later adulthood. Of the 3,043 participants, $80 \%$ were Caucasian, 9.1\% were African American, and the remaining $10.9 \%$ were other ethnicities. With the exception of Self-care (.66) and Realistic Beliefs (.68), the third-order subcategories have alphas ranging from .70 to .87 .

This instruments' construct validity (i.e., convergent and divergent validity) were determined by contrasting the 5F-Wel with other assessments designed to measure similar constructs. Several studies examined factors of wellness within the 5F-Wel in relation to ethnic identity, acculturation, spirituality, moral identity, social interest, academic self-concept, mattering, self-esteem, transitions, chronological age, subjective age, life satisfaction, and relationship self-efficacy and found both higher correlations between similar wellness constructs and lower correlations between different constructs (Hattie, Myers, \& Sweeney, 2004). This suggests the 5F-Wel has sound convergent and divergent validity.

\section{Procedures}

Data were collected during two time periods: the first week of class and the last week of class. During the first day of class, students were informed of the study, they were sent a link to the 5F-Wel by way of their student accounts, and demographic information was obtained from all participants. Upon the last day of class, participants completed the $5 \mathrm{~F}-\mathrm{Wel}$ for a second time. All data were input into a SPSS 20 database for analysis upon the culmination of the study.

\section{Participants}

All participants were in their second semester of their undergraduate studies, were first-time freshman, and received a grade point average below 2.0 during their first semester of enrollment. In addition, these students were attending a southern university, were on academic probation, and were enrolled in a mandatory course designed to help them adjust to college life (i.e., wellness), develop positive study skills, and improve their academic performance with the overall aim of reducing the university's attrition rates. Through their enrollment in this course, students learned about the Five-factor Model of Wellness (5F-Wel; Myers \& Sweeney, 2004), identified ways of improving their own wellness, and discussed connections

between adjusting to college life and their personal academic struggles. This course was designed and instructed by doctoral-level counselors.

The demographic factors for the student-participants were as follows: $43 \%$ percent of the population were male, and $57 \%$ were female. The mean age for participants was 18.46, with a range between 18 and 21 years of age. Of the $n=223$ participants, $10 \%$ were married, $88.8 \%$ were single, . $4 \%$ were separated, and $.4 \%$ were widowed. Further, .9\% identified as Native American, $1.8 \%$ Asian or Pacific Islander, 28.7\% African American, 66.4\% Caucasian, and 2.2\% Hispanic or Latino. 
Regarding employment status, .9\% of the population worked full time, $20.6 \%$ worked part-time, and 78\% were not working. Participants were informed of the nature of the study and their consent was obtained. In addition, no incentives or consequences were offered for participation in this study.

\section{Results}

\section{Sample Integrity}

Data were assessed for homoscedasticity, missing values, normality, linearity, and outliers before conducting analyses. No adjustments to the data were needed (Wilcox, 2003), and homogeneity of variances could be assumed for all of the variables assessed. Therefore, the simple statistical models were used for all analyses.

\section{Research Question 1}

"Does semester GPA predict wellness among college undergraduates on academic probation who are receiving wellness-related counseling and education?" was assessed through a linear regression. The overall model with 23 levels of wellness was not significant: $F(20,202)=1.17, \mathrm{p}>.05, R^{2}=.015$. The only variable in the model that was statically significant was safety. As the safety score decreased, GPA increased $\left(\mathrm{B}=-.01, S E_{B}=.01, \beta=-2.21, \mathrm{p}<.05,95 \% \mathrm{CI}[-.027, .-002]\right)$.

\section{Research Question 2}

The research question "Is there a difference in wellness score within undergraduates on academic probation who are receiving wellness-related counseling and education from pre to post assessment?" was assessed via a paired samples $t$-test. Each of the 23 variables assessed on the 5F-Wel were significantly correlated $p=.00$ from pre to post measure. This suggests participants responded similarly from pre to post measure. There was a significant difference in score $t(222)=-2.41, p<.05$ for Social Self, $t(222)=-2.34, p<.05$ Love, $t(222)=-2.16$, $p<.05$ Cultural Identity, $t(222)=-2.46, p<.05$ Physical Self, and $t(222)=-2.83$, $p<.05$ Exercise. Each of the variables were greater at time one than time two: Social Self at time one $(M=87.10, S D=10.22)$ and time two $(M=84.99, S D=11.31)$, Love at time one $(M=87.72, S D=12.31)$ and time two $(M=85.71, S D=13.10)$, Cultural Identity at time one $(M=82.89, S D=11.99)$ and time two $(M=80.87$, $S D=12.95)$, Physical Self at time one $(M=72.70, S D=12.49)$ and time two $(M=70.75, S D=12.92)$, and Exercise at time one $(M=78.18, S D=13.46)$ and time two $(M=75.70, S D=13.94)$. See Table 1 for further information. 


\section{Summary of 5F-Wel variables pre to post test}

\begin{tabular}{|c|c|c|c|c|}
\hline 5F-Wel & $\begin{array}{c}\text { Time } 1 \\
M\end{array}$ & $\begin{array}{c}\text { Time } 1 \\
S D\end{array}$ & $\begin{array}{c}\text { Time } 2 \\
\qquad M\end{array}$ & $\begin{array}{c}\text { Time } 2 \\
S D\end{array}$ \\
\hline Creative Self & 78.29 & 8.31 & 78.19 & 8.60 \\
\hline Intelligence & 76.79 & 11.17 & 76.93 & 11.11 \\
\hline Emotions & 79.62 & 10.35 & 79.04 & 11.12 \\
\hline Control & 79.93 & 10.90 & 79.61 & 10.87 \\
\hline Work & 73.91 & 11.21 & 73.75 & 12.27 \\
\hline Positive Humor & 81.19 & 11.19 & 81.64 & 10.67 \\
\hline Coping Self & 73.09 & 7.79 & 73.43 & 7.61 \\
\hline Leisure & 77.32 & 10.11 & 78.52 & 10.76 \\
\hline Stress & & & & \\
\hline Management & 74.92 & 14.24 & 75.29 & 13.45 \\
\hline Self-Worth & 85.90 & 11.91 & 84.43 & 11.39 \\
\hline Realistic Beliefs & 56.30 & 11.96 & 57.02 & 11.91 \\
\hline *Social Self & 87.10 & 10.22 & 84.99 & 11.31 \\
\hline Friendship & 86.46 & 10.87 & 84.71 & 11.21 \\
\hline *Love & 87.72 & 12.31 & 85.26 & 13.10 \\
\hline Essential Self & 79.42 & 10.44 & 78.69 & 10.47 \\
\hline Spirituality & 75.90 & 18.09 & 75.62 & 17.24 \\
\hline Gender Identity & 84.36 & 10.61 & 83.46 & 11.48 \\
\hline${ }^{*}$ Cultural Identity & 82.89 & 11.99 & 80.90 & 12.95 \\
\hline Self-care & 76.26 & 16.09 & 76.07 & 15.19 \\
\hline *Physical Self & 72.70 & 12.49 & 70.65 & 12.92 \\
\hline Nutrition & 67.22 & 15.57 & 65.75 & 14.99 \\
\hline${ }^{*}$ Exercise & 78.18 & 13.46 & 75.54 & 13.94 \\
\hline Safety 79.15 & 9.31 & 78.35 & 9.93 & \\
\hline Life Satisfaction & 80.83 & 18.37 & 81.15 & 18.47 \\
\hline Finances & 73.43 & 20.76 & 72.40 & 21.96 \\
\hline Total Wellness & 77.38 & 7.07 & 76.77 & 7.48 \\
\hline
\end{tabular}

Note. ${ }^{*}$ Before $5 \mathrm{~F}-\mathrm{Wel}$ variables indicates these variables were significantly different between pre and post assessment. 
A linear regression was used to analyze the question "Does change in wellness predict change in GPA among college undergraduates on academic probation?" Before calculating each participant's GPA change scores, a one-sample $t$-test was conducted to determine, "Did the participants of our study significantly improve their GPA's from the fall of 2011 to the spring of 2012?" There was a significant difference in score $t(222)=52.73, p<.05$, with GPA being higher during the spring of $2012(M=2.39, S D=.68)$, than the fall of $2011(M=1.38, S D=.49)$. Thus, participants significantly improved in GPA over the course of the study. As delineated in Research Question 3, participants reported lower degrees of wellness among the wellness variables Social Self, Love, Cultural Identity, Physical Self, and Exercise. Of these five variables, only one (Love) proved significant; as Love change decreased, GPA change score increased $\left(B=.02, S E_{B}=.01, \beta=.31, \mathrm{p}<.05,95 \%\right.$ CI $[.00, .03])$. However, the model was not statistically significant: $F(5,217)=1.14$, $\mathrm{p}<.05, R^{2}=.03$. Love scores were higher at time one than time two, suggesting an inverse relationship (i.e., as participants decreased in Love, they increased in GPA). See Table 2 for more information.

TABLE 2

\section{Summary of 5F-Wel change scores predicting GPA change scores}

\section{F-Wel}

Social Self-change

Love Change

Cultural Self-change

Physical Self- change

Exercise Change
B

$$
-.01
$$

$-.00$

.00
$S E_{B}$

$$
.01
$$

.01

.00

.01

.01 $\beta$

$-.21$

.31

$-.05$

$-.07$

.02

\section{Discussion}

This study sought to examine the relationships between wellness and GPA among first-year college students on academic probation. Each of the participants $(n=223)$ were enrolled in a semester-long course, which integrated components designed to cultivate wellness. Although we were conservative in our research approach (i.e., small effect sizes for analyses, large sample sizes, and predictions as opposed to correlations), alternative explanations regarding underlying relationships between the variables cannot be ruled out. In other words, irrefutable conclusions regarding the contributory relationships between the variables 
explored within this study cannot be reached. Thus, future longitudinal and experimental studies that further examine the relationships found within this study with similar and dissimilar populations are recommended in order to further explore whether these findings may generalize to other populations or settings.

The results of this study indicated, whereas students that were mandated to attend the course designed to improve their wellness and study behaviors did not appear to influence their wellness (as measured by the 5F-Wel) from pre to post assessment, students GPA did increase from pre to post assessment. Upon analysis, there was a significant difference in score $t(222)=52.73, p<.05$, with GPA being higher during the spring of $2012(M=2.39, S D=.68)$, than the fall of 2011 $(M=1.38, S D=.49)$. Thus, we believe that although the program was not effective in enhancing students' wellness, it was effective in helping students to increase their GPAs, thereby increasing students' academic success in their second semester. Although longitudinal data is needed to draw direct parallels between students' academic improvement and decreased attrition rates, as previously mentioned, some studies have found a relationship between these variables (i.e., increased student performance and decreased student attrition).

Regarding the relationship between wellness education and academic improvement, given studies that have examined changes in wellness after interventions with similar outcomes (i.e., no change in wellness), we believe wellness might be more stable and less subject to change than we previously thought. As wellness was a large focus of the course, wellness education may or may not be effective in enhancing student achievement. Although definitive and comparative data is needed in order to reach conclusive results, these findings offer preliminary insight into the relationship between wellness education and academic achievement, which could lead to much needed interventions designed to aid college students that are struggling academically.

\section{References}

Abelman, R., \& Molina, A. (2001). Style over substance revisited: A longitudinal analysis of intrusive intervention. NACADA Journal, 21, 32-45.

Adams, T. B., Bezner, J. R., Drabbs, M. E., Zambarano, R. J., \& Steinhardt, M. E. (2000). Conceptualization and measurement of the spiritual and psychological dimensions of wellness in a college population. The Journal of American College Health, 48, 165-173.

American College Health Association (2012). American College Health AssociationNational college health assessment II: Reference group executive summary Fall 2011. Hanover, MD: American College Health Association.

Aguado Loi, C., Spencer, N., \& Willam, A. (2008). Stress management with university students in Canada, US, and Germany: A multinational health education analysis. Umwelt und Gesundheit Online, 1, 60-67. Retrieved from http://electronic-health-journal.com 
Archer, J., Probert, B. S., \& Gage, L. (1987). College students' attitudes toward wellness. Journal of College Student Personnel, 28, 311-317.

Balduf, M. (2009). Underachievement among college students. Journal of Advanced Academics, 20, 274-294.

Brooks, J. H., \& DuBois, D. L. (1995). Individual and environmental predictors of adjustment during the first-year of college. Journal of College Student Development, 36, 347-359.

Cohen, J. (1992). A power primer. Psychological Bulletin, 112, 155-159.

Cousineau, T., Goldstein, B., \& Franko, D. (2004). A collaborative approach to nutrition education for college students. Journal of American College Health, 53, 79-84.

Crocker, J., Luhtanen, R., Cooper, M., \& Bouvrette, A. (2003). Contingencies of selfworth in college students: Theory and measurement. Journal of Personality and Social Psychology, 83, 894-908.

Ferry, L. L., Tobin, J., \& Beesley, D. (2004). Relational predictors of psychological distress in women and men presenting for university counseling center services Journal of College Counseling, 7, 12-140.

Friedman, B. A., \& Mandel, R. G. (2010). The prediction of college student academic performance and retention: Application of expectancy and goal setting theories. Journal of College Student Retention: Research, Theory, \& Practice, $11,227-246$.

Gerdes, H., \& Mallinckrodt, B. (1994). Emotional, social, and academic adjustment of college students: A longitudinal study of retention. Journal of Counseling and Development, 72, 281-288.

Greenberg, J. S. (1985). Health and wellness: A conceptual differentiation. Journal of School Health, 55, 403-406.

Hattie, J., Myers, J., \& Sweeney, T. (2004). A factor structure of wellness: Theory, assessment, analysis and practice. Journal of Counseling and Development, 82, 354-364.

Hermon, D. A., \& Davis, G. A. (2004). College student wellness: A comparison between traditional and nontraditional age students. Journal of College Counseling, 7, 32-38.

Herrero, J., \& Grocica, E. (2004). Predicting social integration in the community among college students. Journal of Community Psychology, 32, 707-720.

Hsieh, P., Sullivan, J. R., \& Guerra, N. S. (2007). A closer look at college students: Self-efficacy and goal orientation. Journal of Advanced Academics, 18, 454-476.

Hudd, S., Dumlao, J., Erdmann-Sager, D., Murray, D., Phan, E., \& Soukas, N. (2000). Stress at college: Effects on health habits, health status and self-esteem. College Student Journal, 34, 217.

Insel, P. \& Roth, W. (2005). Core Concepts in Health. New York, NY: McGraw Hill. James, C. L., \& Graham, S. (2010). An empirical study of students on academic probation. Journal of The First-Year Experience and Students in Transition, 22, 71-92.

Johnson, J. L. (1997). Commuter college students: What factors determine who will persist and who will drop out? College Student Journal, 31, 323-332. 
Khalque, A. (2004). Intimate adult relationships, quality of life and psychological adjustment. Social Indicator Research, 69, 351-360.

Kim, Y. \& Seidlitz, L. (2002). Spirituality moderates the effect of stress on emotional and physical adjustment. Personality \& Individual Differences, 32, 1377-1391.

Kuh, G. D., Kinzie, J., Schuh, J. H., Whitt, E. J., \& Associates. (2005). Student success in college: Creating conditions that matter. Washington, DC: American Association for Higher Education.

Larsons, J. S. (1999). The conceptualization of health. Medical Care Research and Review, 56, 123-136.

Lenth, R. V. (2001). Some practical guidelines for effective sample size determination. The American Statistician, 55, 187-193.

Lewis, T. E. (2010). Wellness factors as predictors of alcohol use among undergraduates: Implications for prevention and intervention. Journal of College Counseling, 13, 111-125.

Myers, J. E. (1991). Wellness as the paradigm for counseling and development: The possible future. Counselor Education and Supervision, 30, 183-193.

Myers, J. E., Luecht, R., \& Sweeney, T.J. (2004). The factor structure of wellness: Reexamining theoretical and empirical models underlying the Wellness Evaluation of Lifestyle (WEL) and the Five-factor Wel. Measurement and Evaluation in Counseling and Development, 36, 194-208.

Myers, J. E., \& Mobley, K. (2004). Wellness of undergraduates: Comparison of traditional and nontraditional students. Journal of College Counseling, 7, 40-49.

Myers, J. E., \& Sweeney, T. J., (2004). Manual for the Five Factor Wellness Inventory 5F-Wel. Greensboro, NC: Author.

Myers, J. E., Sweeney, T. J., \& Witmer, J. M., (2000). The Wheel of Wellness counseling for wellness: A holistic model for treatment planning. Journal of Counseling and Development, 78, 251-266.

Parker, M. W., Fuller, G. F., Koenig, H. G., Bellis, J. N., Vaitkus, M. A., Barko, W. F., \& Eitzen, J. (2001). Soldier and family wellness across the life course: A developmental model of successful aging, spirituality, and health promotion. Part II. Military Medicine, 166, 561-570.

Pascarella, E. T., \& Terenzini, P. T. (2005). How college affects students. San Francisco, CA: Jossey-Bass.

Petrie, T. A., \& Russell, R. K. (1995). Academic and psychosocial antecedents of academic performance for minority and nonminority college football players. Journal Counseling and Development, 72, 615-620.

Proctor, B., Prevatt, F., Adams, K., Hurst, A., \& Petscher, Y. (2006). Study skills profiles of normal-achieving and academically struggling college students. Journal of College Student Development, 47, 37-51.

Rickinson, B., \& Rutherford, D. (1995). Increasing undergraduate student retention rates. British Journal of Guidance and Counseling, 23, 161-172.

Ruthig, J. C., Marrone, S., Hladkyj, S., \& Robbison-Epp, N. (2011). Changes in college student health: Implications for academic performance. Journal of College Student Development, 52(3), 307-320. doi: 10.1352/csd.2011.0038 
Sanderson, C., \& Cantor, N. (1997). Creating satisfaction in steady dating relationships: The role of personal goals and situational affordances. Journal of Personality and Social Psychology, 73, 1424-1433.

Schwitzer, A. M., Griffin, O. T., Ancis, J. R., \& Thomas, C. R. (1999). Social adjustment experiences of African American college students. Journal of Counseling \& Development, 77, 189-197.

Sharkin, B. (2004). College counseling and student retention: Research findings and implications for counseling centers. Journal of College Counseling, 7, 99-108.

Seirup, H., \& Tirotta, R. (2010). Utilizing distance learning as a strategy for academic success for undergraduate students on academic probation: Atypical candidates for online learning. Online Journal of Distance Learning Administration, 13, 213-220.

Smith, C. P., \& Winterbottom, M. T. (1970). Personality characteristics of college student on academic probation. Journal of Personality, 38(3), 379-391. doi: 10.1111/j.1467-6494.1970.tb00016.x

Snyder, C. R., \& Lopez, S. (Eds.). (2002). Handbook of positive psychology. New York, NY: Oxford University Press.

Thome, J., \& Espelage, D. (2004). Relations among exercise, coping, disordered eating, and psychological health among college students. Eating Behaviors, 5, 337-351.

Tinto, V. (1993). Leaving college: Rethinking the causes and cures of student attrition. (2nd Ed.) Chicago, IL: University of Chicago Press.

Tovar, E., \& Simon, M. (2006). Academic probation as a dangerous opportunity: Factors influencing diverse college students' success. Community College Journal of Research \& Practice, 30, 547-564.

Trockel, M., Barnes, M., \& Egget, D. (2000). Health-related variables and academic performance among first-year college students: Implications for sleep and other behaviors. Journal of American College Health, 49, 125-131.

Trombley, C. M. (2001). Evaluating students on probation and determining intervention strategies: A comparison of probation and good standing students. Journal of College Student Retention, 2, 239-251.

Waggoner, D., \& Goldman, P. (2005). Universities as communities of fate: Institutional rhetoric and student retention policy. Journal of Educational Administration, 43(1), 86-101. doi: 10.1108/09578230510577317

Wilcox, R. (2003) Applying contemporary statistical techniques. USA: Elsevier Science.

Wilson, S. B., Mason, T. W., \& Ewing, M. J. M. (1997). Evaluating the impact of receiving university-based counseling services on student retention. Journal of Counseling Psychology, 44, 316-320. 